\title{
Victimization, Urbanicity, and the Relevance of Context: School Routines, Race and Ethnicity, and Adolescent Violence
}

\author{
Anthony A. Peguero, ${ }^{1}$ Edwardo L. Portillos, ${ }^{2}$ Jun S. Hong, ${ }^{3}$ Juan Carlos González, ${ }^{4}$ \\ Lindsay L. Kahle, ${ }^{1}$ and Zahra Shekarkhar ${ }^{5}$ \\ ${ }^{1}$ Department of Sociology, Virginia Tech, Blacksburg, VA 24061, USA \\ ${ }^{2}$ Department of Sociology, University of Colorado, Colorado Springs, Colorado Springs, CO 80918, USA \\ ${ }^{3}$ School of Social Work, Wayne State University, Detroit, MI 48202, USA \\ ${ }^{4}$ Department of Educational Research and Administration, California State University, Fresno, Fresno, CA 93740, USA \\ ${ }^{5}$ Department of Sociology and Criminology \& Law, University of Florida, Gainesville, FL 32611, USA
}

Correspondence should be addressed to Anthony A. Peguero; anthony.peguero@vt.edu

Received 28 February 2013; Revised 31 May 2013; Accepted 8 June 2013

Academic Editor: Byongook Moon

\begin{abstract}
Copyright (C) 2013 Anthony A. Peguero et al. This is an open access article distributed under the Creative Commons Attribution License, which permits unrestricted use, distribution, and reproduction in any medium, provided the original work is properly cited.

The United States is undergoing a historical racial and ethnic demographic shift. There is limited criminological research exploring if and how these changes influence variation in the relationship between routine activity theory and adolescent violence. Although the link between routine activities and victimization has been tested and well established, criminologists have questioned if routine activities can explain adolescent violence across different social contexts. Prior research demonstrates that there are potential nuances in the theoretical connections between routine activities and victimization, particularly when considering race and ethnicity. This study builds on previous research by questioning if the elements of routine activities predict victimization across predominately urban, rural, and suburban schools. The implications of the relevance of school context in the relationships between routine activities and adolescent victimization will also be discussed more generally.
\end{abstract}

\section{Introduction}

Routine activity theory is often utilized to investigate the insulating and risk factors linked to adolescent victimization. In essence, routine activities consider the characteristics of both offenders and victims and/or the characteristics of the space in which offenders and victims are likely to interact and consequently linked to the likelihood of criminal and delinquent activities [1-3]. Adolescents in the USA experience increased risk of criminal victimization, which typically occurs in schools where adolescents spend a significant portion of their lives $[4,5]$. Understanding the factors linked to school victimization is imperative because schools are institutions where adolescent socialization takes place. Criminological research has repeatedly demonstrated that routine activity theory is an appropriate and effective theoretical framework that can explicate the occurrence of adolescent victimization at school $[6,7]$. Recent findings, however, suggest distinctive nuances associated with race and ethnicity in the relationship between routine activities and school victimization [8].

Routine activities theorists have argued that sociodemographic differences (e.g., race, ethnicity, gender, and socioeconomic status) in victimization may be associated with distinct role expectations and structural constraints occurring in the USA $[2,9]$. In other words, social and cultural norms might be associated with individuals' behaviors and daily routines that may lead an individual toward increased or decreased exposure to crime, violence, and victimization. Cohen and colleagues [2] stressed the importance of applying lifestyle and routine activities theories in violence research. They argued that "socio-demographic characteristics are important, because the resulting lifestyle similarity is likely to bring potential offenders and potential victims into direct contact more often than when such characteristics are not shared" ([2], page 509). 
It is also evident that school districts in the USA are undergoing a major demographic shift. According to the US Census Bureau [10], it is projected that, within twenty-five years, racial and ethnic minorities will represent more than half of the total youth population. Thus, understanding the significance of sociodemographic factors in relationship to school victimization is critical. A recent study by Peguero and colleagues [8] found distinctive racial and ethnic nuances in the relationship between routine activities and adolescent school victimization. For instance, academic and sport school routines were found to be potential risks factors for adolescent school victimization for Latino Americans and Asian Americans but not for white Americans [8]. Because sociodemographic characteristics are important aspects of routine activities, investigating the role of race and ethnicity in the relationship between routine activities and adolescent victimization in school is warranted.

Criminology research also reveals racial and ethnic differences in the perceptions of criminal offense, criminal justice responses, and victimization. Interestingly, Peterson et al. [11] argued that "current work (criminological research) often fails to consider how race and ethnicity are themselves central organizing principles within and across societies" (page 1). It is also apparent that school context of violence and the associated school characteristics (e.g., poverty and school size) among urban, rural, and suburban schools are distinct [4, 12-14]. Context and sociodemographics matter in the occurrence of victimization, and the current study extends the literature on routine activities and adolescent violence by examining victimization in urban, rural, and suburban schools. This study first discusses the conceptual link between routine activities and adolescent school victimization, followed by a review of research on the important role of context and sociodemographics in understanding the relevance of routine activities in relation to adolescent school victimization. Data are drawn from the Educational Longitudinal Study of 2002 (ELS), a nationally representative stratified sample of 10,440 tenth grade adolescents in 580 public schools, and hierarchal generalized linear model (HGLM) techniques are employed. Findings indicating racial and ethnic variations in the relationships between routine activities and adolescent victimization across distinct school contexts are presented, and implications for practice, policy, and research are discussed.

\section{Routine Activities and Adolescent Victimization at School}

Routine activity theory proposes that victimization stems from the "recurrent and prevalent activities" that individuals are involved in their daily lives. It is through an individual's routines and activities that influence his or her risk of being victimized [1-3] Routine activity theory suggests that there are three key spatial and temporal elements for violence or crime to occur: (a) suitable target, (b) guardianship, and (c) presence of motivated offenders. Hence, the presence of any one of these spatial and temporal factors increases the likelihood of victimization. Utilizing routine activity theory to research adolescent victimization at school is appropriate because, as in communities, students, faculty, staff, and administrators are involved in common activities, routines, and symbiotic interactions that influence one another and connect all school participants $[6,15,16]$. Thus, for the purposes of this study, adolescents' school routine activities, such as student government, school newspaper, clubs, sports, and misbehavior, might be playing a role in shaping the likelihood of victimization within school. In addition, research also demonstrates that the school context (i.e., urban, rural, and suburban) and sociodemographics (i.e., race and ethnicity) may matter in our understanding of the relationship between routine activities and adolescent school victimization.

Within a routine activities framework, adolescents' school routines and activities may be associated with adolescent's risk of victimization at school by influencing the motivated offender's perceptions of the student as a "suitable victim" and by shaping the level of guardianship the adolescent receives while on school grounds. The perception as a "suitable victim" and the level of guardianship provided by the school may vary by type of school routines and activities the adolescent participates in. Participation in school routine and activities such as school government, band, clubs, and sports should protect students because of the number of adults present (i.e., guardianship). As Wilcox et al. [7] suggest that "even though structured before- and after-school activities are supervised by adults, the relative amount of supervision available can be much less than during normal school hours (i.e., hallways, locker rooms, etc., are typically left unattended while extracurricular activities are ongoing in particular areas of the school or grounds)" (page 248). Felson (1986) purports that "conventional activities can tie down delinquents, but they can also hamstring potential handlers and guardians. Sometimes they bring offender and target together, assemble accomplices, or facilitate transgressions at proximate times and places, after the adults have gone home" (page 125). Therefore, adolescents' school routines and activities may not be the protective factor it has been theorized to be because of the reduction in the level of guardianship provided by the school administrators and the increased exposure and proximity to motivated offenders as a result of being on campus during off-hours.

Peguero and colleagues $[8,17,18]$ found that distinct school routines and activities (e.g., academic, sport, club, and misbehavior) are associated with different types of victimization. For instance, adolescents who participate in schoolbased sports have a decreased risk of criminal victimization, whereas students who participate in academically based extracurricular activities (e.g., school newspaper and government) are at an increased risk $[8,17,19]$. In other words, depending on the particular school routine and activity, the likelihood of victimization is associated with how the school routine and activity shape the motivated offender's perception of the adolescents' suitability as a target, whether the schoolbased routine or activity takes the adolescent to potentially dangerous places within the school, and whether capable adults are present (Astor et al., 1999 [20]) [6-8, 17].

2.1. The Potential Significance of School Context, Race, and Ethnicity. School urbanicity can influence the relationship 
between school routines, activities, and victimization. Although there is extensive research that examined adolescent violence occurring in urban schools (Durán, 2013) $[4,5,13,14$, 21-24], there is a dearth of research that compares the factors associated with adolescent school routine activities and victimization across urban, rural, and suburban school contexts. Examining the potential distinctions across contexts in the relationship between routine activities and victimization is warranted because the characteristics of urban, rural, and suburban schools are significantly different. In general, urban schools will have more problems with violence and victimization because these schools are embedded within communities with higher rates of crime, violence, poverty, unemployment, and disorganization (Durán, 2012) [12, 14, 21-26]. It is also evident that there are limited resources available for urban schools to support extracurricular activities, programs that improve school climates and policies that ensure safe learning environments for students $[5,23]$. On the contrary, suburban schools are often characterized as safer, better organized, affluent, having increased access to resources, and with increased communal bonds [21, 22, 26]. In addition, urban schools often have high concentration of low-income and racial and ethnic minorities [21, 22, 26]. There is emerging research that suggests that rural schools also have similar characteristics as urban schools but consist of predominately low-income and white Americans $[21,22,26,27]$. More specifically, in relationship to the elements of routine activities within school, research indicates that involvement in school routines, engagement in misbehavior, and levels of school security and disorder vary across urban, rural, and suburban schools. What remains uncertain is how the relationship between routine activities and adolescent school victimization differs across school contexts.

Prior research also revealed that the association between being a suitable target for school victimization is moderated by race and ethnicity. Peguero and colleagues [8] suggest that school-based sports are an insulating factor for white American adolescents but a potential risk factor for Latino American and Asian American adolescents. The researchers also found that academic routines and activities are a potential risk factor specifically for racial and ethnic minority adolescents [8]. Although there are racial and ethnic differences with regards to adolescents' engagement in school routines and activities as well as the type of activity, what remains unknown is if and how involvement in school-based academic, sport, and club activities is associated with being a suitable target for adolescent victimization across urban, rural, and suburban school contexts.

There is a symbiotic relationship between engagement in school-based misbehavior and victimization $[6,7,28]$. It is also plausible that the relationship between schoolbased misbehavior and victimization is moderated by race and ethnicity. Research demonstrates that engagement in misbehavior is a risk factor for school victimization for all racial and ethnic groups $[8,25,29]$. Moreover, the researchers also noted that the strength of the association between school misbehavior and victimization varied among racial and ethnic groups. Although it appears that there are little racial and ethnic differences in the relationship between misbehavior and school victimization, it is unclear whether school-based misbehaviors are associated with adolescent victimization across urban, rural, and suburban school contexts.

Increasing guardianship and security has been a common response to school victimization [23,30,31]. However, whether increased school guardianship is an effective solution to school victimization is a matter of debate $[7$, $8,28,30]$. In recent years, there has been a growing trend of increasing school security in public schools by increasing police presence as well as more punitive responses to adolescent school-based misbehaviors (e.g., zero tolerance). An increasing number of public high schools have police officers, armed security guards, metal detectors, surveillance cameras, and random searches (Bracy, 2011 [32]) [23, 30, 31]. Although there is an increasing trend to implement security measures across public schools, researchers have also contended that the number of school security measures is significantly higher in urban schools (Bracy, 2011 [32]) [23, 31]. Although the link between school security and adolescent victimization is found to be inconsistent across studies, it remains unknown if the relationship between school security and adolescent victimization varies across urban, rural, and suburban contexts.

Schools with high levels of social disorder are indeed associated with increased likelihood of victimization due to adolescents' proximity to the motivated offenders (Burrow and Apel, 2008 [34]) [4, 8, 12-14, 33]. Racial and ethnic segregation within communities may be associated with poverty and crime rates [11, 35]. Because schools mirror the communities which they serve, racial and ethnic segregation in school may also be linked to increased school violence and victimization. As noted, there appears to be an association between school disorder, school victimization, and urbanicity. Urban schools with high levels of disorder often place racial and ethnic minorities at increased risk of victimization $[13,14,21,22]$. Although there may be parallels between urban schools, increased social disorder and victimization, what remains unknown is if and how school disorder is associated with the likelihood of adolescent victimization across urban, rural, and suburban contexts.

\section{Current Study}

As previously mentioned, routine activity theory is an appropriate framework for understanding school-based victimization; however, it remains unknown if this theory can elucidate adolescent victimization across distinct urban, rural, and suburban school contexts. With a rapidly growing racial and ethnic minority population in the USA, should the changing demographic landscape be more central to criminological research? As suggested by previous research, race and ethnicity is a moderating factor in the relationship between routine activities and school victimization. Thus, the central focus of this study is to examine whether routine activity theory explains school victimization across distinct urban, rural, and suburban school contexts. 


\section{Method}

Data for this research is drawn from the Educational Longitudinal Study (ELS), a longitudinal survey administered by the Research Triangle Institute (RTI), which is affiliated with the National Center for Education Statistics (NCES) of the US Department of Education. The ELS is designed to monitor the transition of a national sample of adolescents as they progress from tenth grade through twelfth grade and on to postsecondary education and/or employment. These data include information about the backgrounds and experiences of adolescents, their parents and teachers, and descriptions of the schools. ELS data also provides "mappings" to additional external datasets such as the Common Core of Data (CCD). The CCD is the US Department of Education's primary database on public elementary and secondary education, which provides much of school level data (e.g., proportion of Latino Americans, black/African Americans, and Asian Americans, and white Americans enrolled in school).

This study utilized the baseline year of the survey and focused on 12,040 public school students in the ELS sample. Students who did not identify themselves as black/African American, Latino American, Asian American, and white American were omitted, which reduced the sample to 11,320 students. The omission of many of the key variables required for the analysis from the abbreviated form of the student questionnaires led to the exclusion of an additional 880 cases and created the final subsample of 10,440 cases in 580 schools for this analysis. The ELS also includes imputed values (via sequential hot deck imputation) for certain key variables, including family socioeconomic status and student test scores (Ingels et al., 2007) [36]. Therefore, this study imputed these values in the analyses. For other missing data for variables not imputed by the ELS, this study implemented the "impute" command in STATA that organizes cases by patterns of missing data and then runs regressions to determine the predicted values. This study incorporated sample weights to the analyses to account for unequal probabilities of selection and to adjust for nonresponses. These data are especially appropriate for this study in that they allow for an examination of school routines and activities, school contexts, race and ethnicity, and the incidence of school victimization. Results are based on nonlinear hierarchical generalized linear modeling (HGLM) regression analyses. Descriptive statistics are reported in Table 1.

4.1. School-Based Victimization. Students were asked if they had been exposed to various forms of victimization at school during the 2001-2002 academic year. School-based victimization was measured by three items that include (1) someone threatened to hurt me at school, (2) someone hit me, and (3) someone used strong-arm or forceful methods to get money or things from me.

Students indicated whether they were a victim of the aforementioned crimes at school by answering either "never," "once or twice," or "more than twice." Dichotomizing schoolbased victimization data is a common practice because incident victimization data are highly skewed, which may be due to how rare criminal victimization is, particularly multiple criminal victimizations. Hence, the measure of school-based victimization was dichotomized to indicate whether the adolescent was a victim of violence.

4.2. School-Based Routine and Activities. Based on previous research $[7,8,19]$, four categories of school-based routine and activities are constructed: academic, sport, club, and misbehavior.

School-based academic routine and activities (Cronbach's $\alpha=.91$ ) is a count index that was constructed by counting the number of the affirmative responses to five activities adolescents engage in, such as (1) band, orchestra, chorus, or choir, (2) school play or musical, (3) student government, (4) academic- (or achievement-) related honor society, and (5) school yearbook, newspaper, or literary magazine.

School-based sport routine and activities (Cronbach's $\alpha=$ .93) is a count index that was constructed by counting the number of the affirmative responses to eight interscholastic sport activities adolescents engage in, such as (1) baseball, (2) softball, (3) basketball, (4) football, (5) soccer, (6) cheerleading/drill team, (7) other team sports, and (8) individual sport.

School-based club routine and activities (Cronbach's $\alpha=$ .88 ) is a count index that was constructed by counting the number of the affirmative responses to four club activities adolescents engage in, such as (a) service club, (b) school club, (c) hobby club, and (d) vocational education club or vocational student organization.

School-based routine and activities are behaviors that violate school rules but do not necessarily constitute criminal statutes, such as cutting/skipping class, fighting, getting suspended, and other similar behaviors [6-8, 13, 14, 17, 33]. In other words, school-based misbehavior does not necessarily involve behaviors that are illegal but behaviors that are likely to be disruptive to the school environment or result in punishment. School-based misbehavior is a total sum index consisting of five items during the current year $(0=$ never, 1 = 1-2 times, 2 = more than twice): (a) cutting or skipping classes, (b) getting into a physical fight at school, (c) getting into trouble for not following school rules, (d) school suspension, (e) suspension or probation, and (f) transferred to another school for disciplinary reasons. The range for school misbehavior (Cronbach's $\alpha=.80$ ) is from 0 to 10 , with higher values representing greater levels of school-based misbehavior.

4.3. School Security. Similar to previous studies $[7,8]$, a school security index was constructed by counting the number of times school administrators affirmatively responded to the following questions with regards to the implementation of security measures in their schools: (1) control access to school buildings during school hours, (2) control access to school grounds during school hours, (3) require students to pass through metal detectors each day, (4) perform one or more random metal detector checks on students, (5) close the campus for most students during lunch, (6) use one or more random dog sniffs to check for drugs, (7) perform one or more random sweeps for contraband, (8) require clear book bags or ban book bags on school grounds, (9) require students to wear badges or picture IDs, (10) require faculty 
TABLE 1: Descriptive statistics for study variables.

\begin{tabular}{|c|c|c|c|c|c|}
\hline Variables & Range & $\begin{array}{c}\text { Urban schools } \\
\text { M (SD) }\end{array}$ & $\begin{array}{c}\text { Rural schools } \\
\text { M (SD) }\end{array}$ & $\begin{array}{c}\text { Suburban schools } \\
\text { M (SD) }\end{array}$ & $\begin{array}{c}\text { Total } \\
\mathrm{M}(\mathrm{SD})\end{array}$ \\
\hline \multicolumn{6}{|l|}{ Student level } \\
\hline \multicolumn{6}{|l|}{ Dependent } \\
\hline Adolescent victimization & $0-1$ & $.31(.46)$ & $.35(.47)$ & $.34(.47)$ & $.33(.47)$ \\
\hline \multicolumn{6}{|l|}{ Routine activities } \\
\hline School-based academic & $0-5$ & $.47(.81)^{*}$ & $.62(.87)^{*}$ & $.54(.85)$ & $.54(.85)$ \\
\hline School-based sport & $0-8$ & $.81(1.28)^{*}$ & $1.09(1.29)^{*}$ & $1.03(1.32)$ & $.84(1.18)$ \\
\hline School-based club & $0-4$ & $.33(.72)^{*}$ & $.43(.72)^{*}$ & $.39(.73)$ & $.38(.73)$ \\
\hline School-based misbehavior & $0-10$ & $1.60(1.92)^{*}$ & $1.28(1.79)$ & $1.34(1.79)$ & $1.40(1.83)$ \\
\hline \multicolumn{6}{|l|}{ Race and ethnicity } \\
\hline Black/African American & $0-1$ & $.26(.44)^{*}$ & $.09(.29)^{*}$ & $.13(.33)$ & $.16(.36)$ \\
\hline Latino American & $0-1$ & $.26(.43)^{*}$ & $.07(.25)^{*}$ & $.16(.36)$ & $.17(.37)$ \\
\hline Asian American & $0-1$ & $.17(.38)^{*}$ & $.03(.17)^{*}$ & $.12(.32)$ & $.11(.32)$ \\
\hline White American & $0-1$ & $.30(.45)^{*}$ & $.80(.39)^{*}$ & $.60(.49)$ & $.57(.50)$ \\
\hline \multicolumn{6}{|l|}{ Student characteristics } \\
\hline Male & $0-1$ & $.49(50)$ & $.49(.50)$ & $.50(.50)$ & $.49(.50)$ \\
\hline Educational achievement & $21.50-79.94$ & $47.64(10.10)^{*}$ & $50.43(9.47)$ & $50.35(10.08)$ & $49.62(10.03)$ \\
\hline Family socioeconomic Status & $-2.11-1.98$ & $-.19(.73)^{*}$ & $-.09(.64)^{*}$ & $-.01(.72)$ & $-.08(.71)$ \\
\hline Family structure (two parent/guardian) & $0-1$ & $.69(.46)^{*}$ & $.79(.40)$ & $.78(.41)$ & $.75(.43)$ \\
\hline Parental involvement & $0-8$ & $4.67(2.96)^{*}$ & $5.17(2.79)$ & $5.15(2.70)$ & $5.02(2.79)$ \\
\hline \multicolumn{6}{|l|}{ School level } \\
\hline Security & $0-11$ & $3.54(2.68)^{*}$ & $3.50(1.95)^{*}$ & $3.63(2.27)$ & $3.58(2.33)$ \\
\hline Extra security for activities & $0-1$ & $.93(.20)$ & $.83(.37)^{*}$ & $.97(.17)^{*}$ & $.93(.25)$ \\
\hline Social disorder & $0-19$ & $13.43(1.37)^{*}$ & $11.95(1.76)^{*}$ & $12.93(1.63)$ & $12.84(1.68)$ \\
\hline \multicolumn{6}{|l|}{ School characteristics } \\
\hline Poverty & $0-100$ & $34.45(20.31)^{*}$ & $20.95(15.85)$ & $21.60(17.11)$ & $25.03(18.71)$ \\
\hline Size & $50-4,630$ & $1782.77(757.97)^{*}$ & $984.61(898.72)^{*}$ & $1394.70(759.20)$ & $1410.51(839.52)$ \\
\hline Percent black/African American students & $0-100$ & $30.87(.29)^{*}$ & $10.17(.16)^{*}$ & $15.37(.22)$ & $18.51(.24)$ \\
\hline Percent Latino American students & $0-98$ & $23.15(.25)^{*}$ & $7.05(.16)^{*}$ & $12.25(.20)$ & $14.11(.21)$ \\
\hline Percent Asian American students & $0-81$ & $7.51(.12)^{*}$ & $2.33(.07)^{*}$ & $5.01(.11)$ & $5.10(.10)$ \\
\hline Percent white American students & $0-100$ & $37.72(.29)^{*}$ & $78.38(.24)^{*}$ & $65.72(.29)$ & $60.79(.32)$ \\
\hline
\end{tabular}

${ }^{*} P \leq .05$.

Significance tests are based on chi-square tests (for dummy variables) and Welch's $t$-tests (for continuous variables), and verified with nonparametric WilcoxonMann-Whitney tests.

and staff to wear badges or picture IDs, and (11) use one or more security cameras to monitor the school. The security count index (Cronbach's $\alpha=.85$ ) ranges from 0 to 11 with higher scores indicating greater school guardianship.

Extra school security for selected school activities (e.g., athletic and social events, open houses, science fairs, etc.) is a dichotomous variable from the school administrator questionnaire. It is a measure of the school's level of extra guardianship during school-based extracurricular activities.

4.4. Social Disorder. Similar to previous studies $[6,8,14$, 33 ], proximity to motivated student offenders measure is constructed by summing how often school administrators reported whether each of the following was or was not a problem in their schools: (1) tardiness, (2) absenteeism, (3) class cutting, (4) physical conflicts, (5) robbery or theft, (6) vandalism, (7) use of alcohol, (8) use of illegal drugs, (9) students under the influence of drugs/alcohol while at school,
(10) the sale of drugs on campus, (11) possession of weapons, (12) racial-ethnic tensions, (13) student bullying, (14) gang activities, (15) physical abuse of teachers, (16) verbal abuse of teachers, (17) student acts of disrespect for teachers, (18) gang activities, and (19) undesirable cult or extremist group activities. The range for this measure (Cronbach's $\alpha=.83$ ) is from 0 to 19 , with higher values representing higher levels of school disorder.

4.5. Urbanicity. School urbanicity reflects the school location as indicated in the source data for sampling, the CCD. School urbanicity is represented as a three category variable (i.e., urban, suburban, and rural). As designated by the CCD, urban is measured as school located in a large or midsize central city; rural is measured as school located in a rural area, either inside or outside a metropolitan statistical area; and suburban is measured as a school located in a large or small town or is at the urban fringe of a large or midsize city. 
4.6. Race and Ethnicity. Race and ethnicity are reported by students. The sample for these analyses included 1,630 black/African American, 1,730 Latino American, 1,190 Asian American, and 5,890 white American public school students. Racial and ethnic minority groups are oversampled in ELS to obtain a sufficient representation for statistical analyses. In turn, the sample weights used in these analyses are calculated by NCES to compensate for the sampling design and for nonresponse bias (see NCES, 2004) [37]. As noted, the CCD provides the information for the proportion of Latino American, Asian American, black/African American, and white American within a school separately.

4.7. Student and School Characteristics. Previous studies have established that student (i.e., gender, educational achievement, family socioeconomic status, family structure, and family involvement) and school (i.e., poverty, size, locale, and physical disorder) characteristics were associated with school victimization and/or the school experiences of racial and ethnic minorities $[4,6,7,12-14,17,33,38-$ 40]. Thus, these control measures were included in this study.

Gender is coded as male or female based on the adolescent's self-report of their biological sex. Female gender serves as the reference group. Educational achievement is measured using the standardized measure developed by RTI and NCES. ELS included a reading and math composite score based on standardized tests developed by the Educational Testing Service (ETS). The composite score is the average of the math and reading standardized scores, restandardized to a national mean of 50.0 and standard deviation of 10. The NCES preconstructed measure of socioeconomic status is a standardized ( $z$-score) variable based on five equally weighted, standardized components: father's/male guardian's education, mother's/female guardian's education, family income, father's/male guardian's occupational prestige, and mother's/female guardian's occupational prestige. Family structure is a dichotomous variable that measures whether two parents/guardians are present in the adolescent's household. A single parent/guardian household serves as the reference group. Family involvement is an eight-item-count index that measures how active the adolescent's parents/guardians are in his or her education. The items are (a) checking homework, (b) helping with homework, (c) discussing school courses, (d) discussing school activities, (e) discussing topics studied in class, (f) discussing grades, (g) discussing transferring, and $(\mathrm{h})$ discussing college attendance. The count index ranges from 0 to 8 , in which higher scores indicates higher levels of family involvement.

School poverty is measured by the proportion of students within each school who were receiving free or reducepriced lunches. School size is measured by the total student enrollment of the school. School locale is measured by whether the school was located in an urban, rural, or suburban (reference category) location. Independent NCES researchers recorded the prevalence of the school's physical disorder based on 15 physical indicators of disorder (e.g., graffiti on the walls/doors/ceilings, classroom broken lights, graffiti on desks, etc.).
4.8. Analytic Strategy. Since the ELS was designed as a cluster sample in which schools are sampled with unequal probability and the students are sampled or "nested" within these selected schools, the subsample of the ELS violates the assumption of independent observations. Considering the nested structure of the ELS (i.e., students within schools), multilevel modeling was an appropriate analytic tool for this study [41]. HLM 7 was utilized to analyze the multilevel relationships between routine activities and school victimization. As presented in Table 1, because the dependent variable, school victimization, is a dichotomous variable, HGLM was utilized. All Level 1 (student) and Level 2 (school) predictors have been centered on their group means. This allowed us to examine the probability of victimization within each school. This approach can facilitate an interpretation of the grand intercept as the probability that the average student will be victimized within each school while controlling for other relevant student and school variables. The models in this study explicitly recognize that individuals within a particular school may be more similar to one another than individuals in another school and therefore may not provide independent observations.

The processes of the analyses included several steps. First, since school context and urbanicity are central to this study, Table 1 presents the differences between potential factors linked to school-based victimization, routine and activities, and other variables for this study across urban, rural, and suburban school contexts. Table 2 displays the HGLM results of the relationships and interactions between routine and activities, school victimization, race, ethnicity, and other relevant factors in urban, rural, and suburban schools. In Model 2, school-based victimization was regressed on routine activities measures. In Model 2, race, ethnicity, and other student- and school-related control variables were added to the analysis. In Model 3, the interactions between schoolbased routines and activities (i.e., academic, sport, club, and misbehavior) and race and ethnicity were analyzed. These analytical steps were implemented across rural and suburban school contexts and are presented in Tables 3 and 4 , respectively.

\section{Results}

5.1. Descriptive Statistics. As presented in Table 1, 33\% of the adolescents in this sample reported having been victimized at school, and $31 \%$ of adolescents in urban schools and $35 \%$ of adolescents in rural schools reported experiencing victimization. In relation to routine activities measures, adolescents in urban schools had the lowest levels of academic, sport, and club involvement at school; on the other hand, adolescents in urban schools had the highest level of misbehavior. Descriptive statistics also indicated that adolescents in urban schools had lower levels of being in two-parent/guardian family structures and parental involvement than their rural and suburban counterparts. At the school level, urban and rural schools had lower levels of security than their suburban counterparts. Rural schools had the lowest level of extra security for activities. Urban schools had the highest levels of social disorder, while rural schools had the lowest levels. 
TABLE 2: Hierarchical generalized linear model effects (standard errors) and odds ratio for adolescent victimization in urban schools.

\begin{tabular}{|c|c|c|c|c|c|c|}
\hline \multirow{2}{*}{ 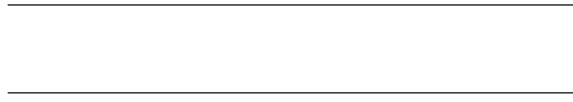 } & \multicolumn{2}{|c|}{ Model 1} & \multicolumn{2}{|c|}{ Model 2} & \multicolumn{2}{|c|}{ Model 3} \\
\hline & $\beta(\mathrm{SE})$ & OR & $\beta(\mathrm{SE})$ & OR & $\beta(\mathrm{SE})$ & OR \\
\hline \multicolumn{7}{|l|}{ Within urban schools } \\
\hline \multicolumn{7}{|l|}{ Routine activities } \\
\hline School-based academic & $.034(.068)$ & 1.035 & $.045(.070)^{* *}$ & 1.047 & $-.163(.112)^{\dagger}$ & .848 \\
\hline Black/African American & - & - & - & - & $.296(.170)^{*}$ & 1.344 \\
\hline Latino American & - & - & - & - & $.306(.194)^{\dagger}$ & 1.358 \\
\hline Asian American & - & - & - & - & $.586(.177)^{* * *}$ & 1.798 \\
\hline School-based sport & $.034(.037)$ & 1.035 & $.023(.037)$ & 1.023 & $.049(.071)$ & 1.050 \\
\hline Black/African American & - & - & - & - & $-.106(.095)$ & .899 \\
\hline Latino American & - & - & - & - & $.015(.108)$ & 1.015 \\
\hline Asian American & - & - & - & - & $.023(.120)$ & 1.023 \\
\hline School-based club & $-.012(.080)$ & .987 & $.026(.082)$ & 1.027 & $-.115(.118)$ & .890 \\
\hline Black/African American & - & - & - & - & $.243(.196)$ & 1.276 \\
\hline Latino American & - & - & - & - & $.119(.187)$ & 1.126 \\
\hline Asian American & - & - & - & - & $.240(.162)$ & 1.271 \\
\hline School-based misbehavior & $.328(.027)^{* * *}$ & 1.389 & $.315(.028)^{* * *}$ & 1.370 & $.402(.054)^{* * *}$ & 1.495 \\
\hline Black/African American & - & - & - & - & $-.147(.068)^{*}$ & .862 \\
\hline Latino American & - & - & - & - & $-.102(.077)$ & .902 \\
\hline Asian American & - & - & - & - & $-.087(.092)$ & .916 \\
\hline \multicolumn{7}{|l|}{ Race and ethnicity } \\
\hline Black/African American & - & - & $-.253(.187)$ & .776 & $-.071(.262)$ & .930 \\
\hline Latino American & - & - & $-.285(.193)^{\dagger}$ & .751 & $-.272(.267)$ & .761 \\
\hline Asian American & - & - & $-.309(.195)^{\dagger}$ & .733 & $-.595(.297)^{*}$ & .551 \\
\hline \multicolumn{7}{|l|}{ Student characteristics } \\
\hline Male & - & - & $.450(.117)^{* * *}$ & 1.568 & $.431(.117)^{* * *}$ & 1.539 \\
\hline Educational achievement & - & - & $-.012(.005)^{*}$ & .987 & $-.009(.005)^{\dagger}$ & .990 \\
\hline Family socioeconomic status & - & - & $.117(.078)^{\dagger}$ & 1.124 & $.129(.078)^{\dagger}$ & 1.138 \\
\hline Family structure & - & - & $.118(.116)$ & 1.126 & $.124(.116)$ & 1.133 \\
\hline Family involvement & - & - & $.024(.015)^{\dagger}$ & 1.024 & $.020(.015)$ & 1.020 \\
\hline \multicolumn{7}{|l|}{ Between urban schools } \\
\hline Security & $.026(.018)^{\dagger}$ & 1.026 & $.027(.019)$ & 1.028 & $.027(.019)$ & 1.027 \\
\hline Extra security for activities & $.105(.229)$ & 1.111 & $.227(.206)$ & 1.255 & $.217(.201)$ & 1.243 \\
\hline Social disorder & $.109(.034)^{* * *}$ & 1.115 & $.134(.040)^{* * *}$ & 1.144 & $.131(.040)^{* * *}$ & 1.140 \\
\hline \multicolumn{7}{|l|}{ School characteristics } \\
\hline Poverty & - & - & $-.001(.003)$ & .999 & $-.001(.003)$ & .999 \\
\hline Size & - & - & $-.001(.001)$ & .999 & $-.001(.001)$ & .999 \\
\hline Percent black/African American students & - & - & $-.116(.286)$ & .889 & $-.083(.287)$ & .919 \\
\hline Percent Latino American students & - & - & $.175(.266)$ & 1.192 & $.212(.268)$ & 1.236 \\
\hline Percent Asian American students & - & - & $-.729(.608)$ & .481 & $-.778(.601)$ & .459 \\
\hline Intercept & $-.827(.050)^{* * *}$ & & $-.877(.050)^{* * *}$ & & $-.878(.050)^{* * *}$ & \\
\hline \multirow[t]{2}{*}{ Random effects } & Variance & $X^{2}$ & Variance & $X^{2}$ & Variance & $X^{2}$ \\
\hline & $.093^{* * *}$ & 217.889 & $.108^{* * *}$ & 222.435 & $.112^{* * *}$ & 222.229 \\
\hline
\end{tabular}

${ }^{\dagger} P \leq .1 ;{ }^{*} P \leq .05 ;{ }^{* *} P \leq .01 ;{ }^{* *} P \leq .001$.

The omitted categories are white American, females, single parent/guardian family structures, and no extra security for selected school activities.

School descriptive statistics also indicated that urban schools had higher levels of poverty and physical disorder and were relatively larger.

5.2. Routine Activities and Adolescent Victimization in Urban Schools. Table 2 presents the HGLM regression analysis of routine activities and adolescent victimization in urban schools. The baseline model explored the role of routine activities in the likelihood of urban adolescent school victimization. For suitable target, only increasing engagement in school-based misbehavior was associated with the increased likelihood of victimization by $38.9 \%$ in urban schools $(\beta=$ .328, $P \leq .001)$. For school security, urban adolescents who attend schools with higher levels of security at their schools 
TABLE 3: Hierarchical generalized linear model effects (standard errors) and odds ratio for adolescent victimization in rural schools.

\begin{tabular}{|c|c|c|c|c|c|c|}
\hline \multirow{2}{*}{ 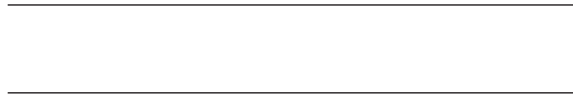 } & \multicolumn{2}{|c|}{ Model 4} & \multicolumn{2}{|c|}{ Model 5} & \multicolumn{2}{|c|}{ Model 6} \\
\hline & $\beta(\mathrm{SE})$ & OR & $\beta(\mathrm{SE})$ & OR & $\beta(\mathrm{SE})$ & OR \\
\hline \multicolumn{7}{|l|}{ Within rural schools } \\
\hline \multicolumn{7}{|l|}{ Routine activities } \\
\hline School-based academic & $.060(.060)$ & 1.062 & $.147(.066)^{*}$ & 1.158 & $.144(.070)^{*}$ & 1.155 \\
\hline Black/African American & - & - & - & - & $.334(.205)^{\dagger}$ & 1.397 \\
\hline Latino American & - & - & - & - & $-.541(.255)^{*}$ & .582 \\
\hline Asian American & - & - & - & - & $1.198(.571)^{*}$ & 3.315 \\
\hline School-based sport & $-.017(.044)$ & .982 & $-.038(.046)$ & .961 & $-.014(.051)$ & .985 \\
\hline Black/African American & - & - & - & - & $-.381(.170)^{*}$ & .682 \\
\hline Latino American & - & - & - & - & $.180(.158)$ & 1.197 \\
\hline Asian American & - & - & - & - & $.031(.281)$ & 1.031 \\
\hline School-based club & $.128(.068)^{*}$ & 1.137 & $.177(.071)^{* *}$ & 1.194 & $.211(.081)^{* *}$ & 1.235 \\
\hline Black/African American & - & - & - & - & $-.282(.178)^{\dagger}$ & .776 \\
\hline Latino American & - & - & - & - & $-.004(.356)$ & .995 \\
\hline Asian American & - & - & - & - & $-.987(.698)^{*}$ & .109 \\
\hline School-based misbehavior & $.419(.035)^{* * *}$ & 1.521 & $.392(.035)^{* * *}$ & 1.480 & $.411(.041)^{* * *}$ & 1.509 \\
\hline Black/African American & - & - & - & - & $-.174(.095)^{*}$ & .839 \\
\hline Latino American & - & - & - & - & $.025(.103)$ & 1.025 \\
\hline Asian American & - & - & - & - & $-.054(.184)$ & .946 \\
\hline \multicolumn{7}{|l|}{ Race and ethnicity } \\
\hline Black/African American & - & - & $-.123(.179)$ & .883 & $.468(.254)^{*}$ & 1.598 \\
\hline Latino American & - & - & $-.481(.236)^{*}$ & .618 & $-.484(.306)^{\dagger}$ & .616 \\
\hline Asian American & - & - & $-.573(.347)^{*}$ & .563 & $-.265(.662)$ & .766 \\
\hline \multicolumn{7}{|l|}{ Student characteristics } \\
\hline Male & - & - & $.649(.111)^{* * *}$ & 1.914 & $.648(.113)^{* * *}$ & 1.912 \\
\hline Educational achievement & - & - & $-.011(.006)^{*}$ & .988 & $-.011(.006)^{*}$ & .988 \\
\hline Family socioeconomic status & - & - & $.068(.083)$ & 1.070 & $.073(.083)$ & 1.076 \\
\hline Family structure & - & - & $.019(.138)$ & 1.019 & $-.011(.137)$ & .988 \\
\hline Family involvement & - & - & $-.014(.021)$ & .985 & $-.014(.021)$ & .985 \\
\hline \multicolumn{7}{|l|}{ Between rural schools } \\
\hline Security & $-.023(.026)$ & .976 & $-.028(.028)$ & .971 & $-.028(.029)$ & .972 \\
\hline Extra security for activities & $-.444(.120)^{* * *}$ & .641 & $-.493(.139)^{* * *}$ & .610 & $-.493(.141)^{* * *}$ & .610 \\
\hline Social disorder & $.017(.032)$ & 1.017 & $.022(.036)$ & 1.022 & $.024(.037)$ & 1.025 \\
\hline \multicolumn{7}{|l|}{ School characteristics } \\
\hline Poverty & - & - & $.001(.004)$ & 1.001 & $.001(.004)$ & 1.001 \\
\hline Size & - & - & $-.001(.001)$ & .999 & $-.001(.001)$ & .999 \\
\hline Percent black/African American students & - & - & $.678(.414)^{\dagger}$ & 1.970 & $.674(.414)^{\dagger}$ & 1.963 \\
\hline Percent Latino American students & - & - & $-.216(.492)$ & .805 & $-.252(.520)$ & .777 \\
\hline Percent Asian American students & - & - & $.767(.618)$ & 2.155 & $.530(.644)$ & 1.701 \\
\hline Intercept & $-.679(.057)^{* * *}$ & & $-.709(.058)^{* * *}$ & & $-.725(.058)^{* * *}$ & \\
\hline \multirow[t]{2}{*}{ Random effects } & Variance & $X^{2}$ & Variance & $X^{2}$ & Variance & $X^{2}$ \\
\hline & $.104^{* * *}$ & 171.073 & $.121^{* * *}$ & 172.729 & $.129^{* * *}$ & 174.343 \\
\hline
\end{tabular}

${ }^{\dagger} P \leq .1 ;{ }^{*} P \leq .05 ;{ }^{* *} P \leq .01 ;{ }^{* * *} P \leq .001$.

The omitted categories are white American, females, single parent/guardian family structures, and no extra security for selected school activities.

had increased odds of being victimized $(\beta=.026, P \leq .1)$. For social disorder, urban adolescents who attend schools with higher levels of disorder at their schools had increased odds of being victimized $(\beta=.109, P \leq .001)$. In this stage of the analysis, academic, sport, and club activities and extra school security for activities were not found to be associated with adolescents' likelihood of victimization in urban schools.

In Model 2 (see Table 2), control variables were added to the analysis. For suitable target, increasing schoolbased academic activities emerged as significantly associated with increased odds of being victimized in urban schools 
TABLE 4: Hierarchical generalized linear model effects (standard errors) and odds ratio for adolescent victimization in suburban schools.

\begin{tabular}{|c|c|c|c|c|c|c|}
\hline & \multicolumn{2}{|c|}{ Model 7} & \multicolumn{2}{|c|}{ Model 8} & \multicolumn{2}{|c|}{ Model 9} \\
\hline & $\beta(\mathrm{SE})$ & OR & $\beta(\mathrm{SE})$ & OR & $\beta(\mathrm{SE})$ & OR \\
\hline \multicolumn{7}{|l|}{ Within suburban schools } \\
\hline \multicolumn{7}{|l|}{ Routine activities } \\
\hline School-based academic & $.082(.045)^{*}$ & 1.085 & $.148(.045)^{* * *}$ & 1.160 & $.096(.055)^{*}$ & 1.101 \\
\hline Black/African American & - & - & - & - & $.121(.122)$ & 1.129 \\
\hline Latino American & - & - & - & - & $.230(.149)^{\dagger}$ & 1.259 \\
\hline Asian American & - & - & - & - & $.098(.166)$ & 1.103 \\
\hline School-based sport & $-.016(.029)$ & .983 & $-.044(.029)^{\dagger}$ & .956 & $-.097(.035)^{* *}$ & .906 \\
\hline Black/African American & - & - & - & - & $.132(.074)^{*}$ & 1.141 \\
\hline Latino American & - & - & - & - & $.154(.066)^{* *}$ & 1.167 \\
\hline Asian American & - & - & - & - & $.135(.123)$ & 1.145 \\
\hline School-based club & $-.029(.054)$ & .970 & $.014(.054)$ & 1.014 & $-.002(.069)$ & .997 \\
\hline Black/African American & - & - & - & - & $.039(.157)$ & 1.039 \\
\hline Latino American & - & - & - & - & $-.058(.181)$ & .943 \\
\hline Asian American & - & - & - & - & $.078(.176)$ & 1.081 \\
\hline School-based misbehavior & $.321(.021)^{* * *}$ & 1.378 & $.292(.021)^{* * *}$ & 1.339 & $.293(.027)^{* * *}$ & 1.341 \\
\hline Black/African American & - & - & - & - & $-.008(.054)$ & .991 \\
\hline Latino American & - & - & - & - & $-.002(.051)$ & .997 \\
\hline Asian American & - & - & - & - & $-.063(.095)$ & .938 \\
\hline \multicolumn{7}{|l|}{ Race and ethnicity } \\
\hline Black/African American & - & - & $-.136(.125)$ & .872 & $-.329(.193)^{*}$ & .719 \\
\hline Latino American & - & - & $-.101(.165)$ & .903 & $-.329(.218)^{\dagger}$ & .718 \\
\hline Asian American & - & - & $-.149(.158)$ & .861 & $-.290(.230)$ & .748 \\
\hline \multicolumn{7}{|l|}{ Student characteristics } \\
\hline Male & - & - & $.626(.077)^{* * *}$ & 1.871 & $.613(.077)^{* * *}$ & 1.846 \\
\hline Educational achievement & - & - & $-.013(.004)^{* *}$ & .986 & $-.012(.004)^{* *}$ & .987 \\
\hline Family socioeconomic status & - & - & $.017(.060)$ & 1.017 & $.022(.060)$ & 1.022 \\
\hline Family structure & - & - & $-.056(.091)$ & .945 & $-.054(.091)$ & .946 \\
\hline Family involvement & - & - & $.020(.014)^{\dagger}$ & 1.020 & $.021(.014)^{\dagger}$ & 1.022 \\
\hline \multicolumn{7}{|l|}{ Between suburban schools } \\
\hline Security & $-.011(.015)$ & .988 & $-.013(.014)$ & .986 & $-.013(.014)$ & .986 \\
\hline Extra security for activities & $.144(.250)$ & 1.155 & $.207(.234)$ & 1.230 & $.215(.235)$ & 1.241 \\
\hline Social disorder & $-.016(.022)$ & .983 & $.020(.025)$ & 1.021 & $.020(.025)$ & 1.020 \\
\hline \multicolumn{7}{|l|}{ School characteristics } \\
\hline Poverty & - & - & $.002(.003)$ & 1.002 & $.002(.003)$ & 1.002 \\
\hline Size & - & - & $-.001(.001)^{\dagger}$ & .995 & $-.001(.001)^{\dagger}$ & .995 \\
\hline Percent black/African American students & - & - & $-.306(.233)$ & .736 & $-.305(.232)$ & .736 \\
\hline Percent Latino American students & - & - & $-.683(.269)^{*}$ & .504 & $-.680(.270)^{* *}$ & .506 \\
\hline Percent Asian American students & - & - & $-.209(.331)$ & .810 & $-.192(.324)$ & .825 \\
\hline Intercept & $-.686(.038)^{* * *}$ & & $-.710(.037)^{* * *}$ & & $-.711(.037)^{* * *}$ & \\
\hline \multirow[t]{2}{*}{ Random effects } & Variance & $X^{2}$ & Variance & $X^{2}$ & Variance & $X^{2}$ \\
\hline & $.135^{* * *}$ & 450.687 & $.123^{* * *}$ & 428.597 & $.122^{* * *}$ & 426.673 \\
\hline
\end{tabular}

${ }^{\dagger} P \leq .1 ;{ }^{*} P \leq .05 ;{ }^{* *} P \leq .01 ;{ }^{* * *} P \leq .001$.

The omitted categories are white American, females, single parent/guardian family structures, and no extra security for selected school activities.

$(\beta=.045, P \leq .01)$. Increasing engagement in school-based misbehavior remained significantly associated with increased likelihood of victimization in urban schools $(\beta=.315, P \leq$ $.001)$. For race and ethnicity, Latino Americans $(\beta=$ $-.285, P \leq .1)$ and Asian Americans $(\beta=-.309, P \leq$ .1) were less likely to be victimized in comparison to white Americans in urban schools. At this stage of the analysis, school security was no longer associated with adolescent victimization in urban schools. For social disorder, urban adolescents who attend schools with higher levels of disorder at their schools had increased odds of being victimized $(\beta=.134, P \leq .001)$. For control characteristics, males and adolescents with higher family socioeconomic status and increased family involvement were associated with increased 
odds, while higher educationally achieving adolescents were linked to decreased odds, for victimization in urban schools.

In Model 3 (see Table 2), the student interactions between routine activities, race, and ethnicity in urban schools were introduced into the analysis. The relationships between academic and club activities and victimization in urban schools varied by race and ethnicity. The main effect of schoolbased academic activities $(\beta=-.163, P \leq .1)$ was significantly related to decreased school victimization for white American urban adolescents; however, the interaction results indicate racial and ethnic variations. Increased schoolbased academic activities placed black/African American $(\beta=.130, P \leq .05)$, Latino American $(\beta=.143, P \leq .1)$, and Asian American $(\beta=.423, P \leq .001)$ adolescents at increased risk of urban school victimization. The main effect of school-based misbehavior $(\beta=.402, P \leq .001)$ remained significantly related to increased victimization for white American adolescents in urban schools. It also appears that misbehavior also placed black/African American, Latino American, and Asian American adolescents at risk of urban school victimization; however, the effect of misbehavior for black/African American urban adolescents was not as strong on the relationship with urban school victimization. It is also important to note that being black/African American and Latino American was not linked to adolescent victimization; however, Asian Americans did have decreased odds of being victimized in urban schools $(\beta=-.595, P \leq .05)$. For control characteristics, males and adolescents with higher family socioeconomic status were associated with increased odds, while higher educationally achieving adolescents was linked to decreased odds for victimization in urban schools.

5.3. Routine Activities and Adolescent Victimization in Rural Schools. Table 3 presents the HGLM regression analysis of routine activities and adolescent victimization in rural schools. The baseline Model 4 explored the role of routine activities in the likelihood of rural adolescent school victimization. For suitable target, increasing engagement in schoolbased club activities $(\beta=.128, P \leq .05)$ and misbehavior $(\beta=.419, P \leq .001)$ was associated with increased victimization in rural schools. For extra security for activities, rural adolescents who attend schools with higher levels of extra security for activities at their schools had decreased odds of being victimized $(\beta=-.444, P \leq .001)$. In this stage of the analysis, academic and sport activities, school security, and school social disorder were not found to be associated with adolescents' likelihood of victimization in rural schools.

In Model 5 (see Table 3), control variables were added to the analysis. For suitable target, increasing school-based academic activities emerged as significantly associated with increased odds of being victimized in rural schools $(\beta=$ .147, $P \leq .05)$. Increasing school-based club $(\beta=.177, P \leq$ $.01)$ and misbehavior $(\beta=.392, P \leq .001)$ activities remained significantly associated with increased odds of being victimized in rural schools. For race and ethnicity, Latino Americans $(\beta=-.481, P \leq .05)$ and Asian Americans $(\beta=-.573, P \leq .05)$ were less likely to be victimized in comparison to white Americans in rural schools. At this stage of the analysis, increased extra security for activities remained negatively associated with adolescent victimization in rural schools $(\beta=-.493, P \leq .001)$. For control characteristics, male gender was associated with higher odds, while higher educationally achieving adolescents had lower odds, of being victimized in rural schools. Also, rural schools with higher proportions of black/African American students had increased odds of victimization in rural schools.

In Model 6 (see Table 3), student interactions between routine activities, race, and ethnicity in rural schools were introduced into the analysis. The relationships between academic, sport, and club activities and victimization in rural schools varied by race and ethnicity. The main effect of school-based academic activities $(\beta=.144, P \leq$ $.05)$ was significantly related to an increase in school victimization for white American rural adolescents; however, the interaction results indicated racial and ethnic variations. Increased school-based academic activities placed black/African American and Asian American adolescents at greater risk of victimization in rural schools than their white American adolescent counterparts. On the contrary, increased school-based academic activities placed Latino American adolescents at decreased risk of victimization in rural schools $(\beta=-.397, P \leq .05)$. Increased schoolbased sport activities were associated with decreased odds of victimization for black/African Americans in rural schools ( $\beta=-.381, P \leq .05)$. The main effect of school-based club activities $(\beta=.211, P \leq .01)$ was significantly related to increased school victimization for white Americans; however, the results indicated racial and ethnic variations. Increased school-based club activities placed black/African American $(\beta=-.071, P \leq .1)$ and Asian American $(\beta=$ $.776, P \leq .01)$ adolescents at reduced risk of victimization in rural schools. There was no statistically significant difference between Latino Americans and white Americans in the relationship between school-based club activities and victimization, which indicated that school-club activities also placed Latino American adolescents at risk for victimization in rural schools. The main effect of school-based misbehavior $(\beta=.411, P \leq .001)$ remained significantly related to increased victimization among white American adolescents in rural schools. It also appears that misbehavior also placed black/African American, Latino American, and Asian American adolescents at risk of victimization in rural schools; however, the effect of misbehavior for black/African American rural adolescents was not as strong with regards to the relationship with rural school victimization. It is also important to note that being black/African American $(\beta=$ .468, $P \leq .05)$ was found to have an increased risk, while being Latino American $(\beta=-.484, P \leq .1)$ had a decreased risk, of victimization in rural schools. Increased extra security for activities remained negatively associated with adolescent victimization in rural schools $(\beta=-.493, P \leq .001)$. For control characteristics, male gender was found to have increased risk, while higher educational achievement had decreased risk for victimization in rural schools. Also, rural schools with higher proportions of black/African American students had increased odds of victimization in rural schools. 
5.4. Routine Activities and Adolescent Victimization in Suburban Schools. Table 4 presents the HGLM regression analysis of routine activities and adolescent victimization in suburban schools. The baseline Model 7 explored the role of routine activities in the likelihood of suburban adolescent school victimization. For suitable target, increasing engagement in school-based academic activities $(\beta=.082, P \leq .05)$ and misbehavior $(\beta=.321, P \leq .001)$ were associated with increased victimization in suburban schools. In this stage of the analysis, sport and club activities, school security and extra security for activities, and school social disorder were not found to be associated with adolescents' likelihood of victimization in suburban schools.

In Model 8 (see Table 4), control variables were added to analysis. For suitable target, increasing school-based academic activities remained significantly associated with increased odds of being victimized in suburban schools $(\beta=$ $.148, P \leq .001)$. Increasing school-based sport activities emerged as an insulting factor for victimization in suburban schools $(\beta=-.044, P \leq .1)$. Increased school-based misbehavior $(\beta=.292, P \leq .001)$ activities remained significantly associated with increased odds of being victimized in suburban schools. Race and ethnicity were not associated with victimization in suburban schools. In this stage of the analysis, club activities, school security and extra security for activities, and school social disorder were not found to be associated with adolescents' likelihood of victimization in suburban schools. For control characteristics, male gender and higher levels of family involvement were associated with higher odds, while higher educational achievement had lower odds, of being victimized in suburban schools. Also, larger suburban schools and suburban schools with higher proportions of Latino American students had decreased odds of adolescents being victimized in suburban schools.

In Model 9 (see Table 4), student interactions between routine activities, race, and ethnicity in suburban schools were introduced into the analysis. The relationships between academic and sport activities and victimization in suburban schools varied by race and ethnicity. The main effect of school-based academic activities $(\beta=.096, P \leq .05)$ was significantly related to increased school victimization for white American suburban adolescents; however, the interaction results indicated racial and ethnic variations. The results suggest that increased school-based academic activities placed Latino American adolescents at greater risk of victimization in suburban schools than their white American adolescent counterparts $(\beta=.134, P \leq .1)$. Because there was no statistically significant difference between black/African Americans, Asian Americans, and white Americans in the relationship between school-based academic activities and victimization, this indicates that school-based academic activities also placed black/African Americans and Asian Americans at risk for victimization at suburban schools. The main effect of school-based sport activities $(\beta=-.097, P \leq .01)$ was significantly related to decreased school victimization for white American suburban adolescents; however, the interaction results indicated racial and ethnic variations. The results suggest that increased school-based sport activities placed black/African American $(\beta=.035, P \leq .05)$ and Latino American $(\beta=.57, P \leq .01)$ adolescents at increased risk of victimization in suburban schools. There is no statistically significant difference between Asian Americans and white Americans in the relationship between school-based sport activities and victimization, which indicated that school-based sport activities also placed Asian American adolescents at decreased risk for victimization at suburban schools. The main effect of school-based misbehavior $(\beta=.293, P \leq .001)$ remained significantly related to increased victimization among white American adolescents in suburban schools. There appear to be no significant racial and ethnic differences in this relationship between misbehavior and victimization. In this stage of the analysis, club activities, school security and extra security for activities, and school social disorder were not found to be associated with adolescents' likelihood of victimization in suburban schools. For control characteristics, male gender and higher levels of family involvement were associated with higher odds, while higher educational achievement was associated with lower odds, of being victimized in suburban schools. Also, larger suburban schools and suburban schools with higher proportions of Latino American students had decreased odds of adolescent victimization in suburban schools.

\section{Discussion}

This study examined the relevance of routine activities in understanding adolescent victimization across distinct school contexts. As noted by many prior routine activities researchers, context matters when investigating the correlates of adolescent victimization within schools $[6,7,9,19]$. Studies have also found that race and ethnicity moderated the relationship between routine activities and school victimization $[4,6,8,13,14,29]$. In sum, the routine activities have been found to be an effective theoretical tool for understanding the risk and insulating factors associated with victimization across distinct school contexts; however, there are subtle nuances that warrant further discussion.

Finkelhor and Asdigian [42] argued that the offender motivation matters in the link between routine activities and adolescent victimization. They suggest that more attention needs to be given to the risk-increasing potential of individual characteristics and attributes, such as socioeconomic status, because these characteristics have some congruence with motivation for offender targeting their victims [42]. Examining personal characteristics of adolescents in distinct environmental contexts is essential for understanding the relationship between routine activities and adolescent victimization [42]. They describe that "target vulnerability" is associated with vulnerability factors such as small physical statue, physical weakness, emotional deprivation, or psychological problems; "target gratifiability" is associated with vulnerability factors, such as female gender for the crime of sexual assault; and "target antagonism" is associated with vulnerability factors, such as possessions, skills, or attributes that arouse the anger, jealousy, or destructive impulses of the offender ([42], page 6). Unfortunately, the data utilized in this analysis did not provide necessary offender information 
to adequately test Finkelhor and Asdigian's [42] theoretical concepts. However, their approach does provide some insight to this study's complex findings of the nuances between routine activities, adolescent victimization, and race and ethnicity across distinct schools contexts. There are sociocultural differences to how academic, sport, and club school activities are perceived in distinct school contexts. Distinct school activities are associated with distinct interactions and resulting capital, depending on the school culture and climate $[18,43,44]$. In other words, the ways in which interscholastic sport athletes or school band members are perceived by other students differ from school to school. Understanding how all school participants perceive and value students who are involved in each type of extracurricular activity is vital in understanding the relationship between involvement in different school activities and victimization. Moreover, prior research also suggests that race and ethnicity confound the complexities between sociocultural perceptions and understanding of school activities [18, 43, 44].

Engagement in school-based misbehavior is found to increase the odds of victimization at school across each of the distinct school demographic contexts. This finding suggests that the relationship between exposure and adolescent victimization may not be moderated by distinct school contexts. Numerous researches suggest that adolescent misbehavior increases the risk of victimization $[6,7,28,40]$. It may be that students who misbehave are perceived by other students as "troublemakers" or "nuisances" who consistently disrupt other students' academic and social lives. This study extends prior studies that examined the link between misbehavior and victimization, and results indicate that this relationship is significant across distinct school contexts.

Consistent with prior research [7, 8, 28, 30], this study also found weak associations between security and school victimization. There is no evidence which suggests that increased security is associated with decreased adolescent victimization at urban and suburban schools; however, extra security for school activities such as athletic and social events, open houses, science fairs, and the like were linked to decreased odds of adolescent victimization in rural schools. Researchers have argued serious detriments with increased school security, particularly in urban schools. Portillos et al. [31] report that adolescents within urban and predominantly racial and ethnic minority schools view their schools as unfair and suggest that heightened school securitization reinforces a sense of marginalization and criminalization. Increased security and social control practices, particularly in urban and predominately racial and ethnic minority schools, appear to be detrimental for adolescents who may perceive their school environment as a prison-like setting [23,30]. In light of this study's findings of the weak support of increased security being associated with decreased victimization, further investigation of the role of increased security in relationship to other school-related outcomes is warranted.

And finally, this study found an association between proximity and school victimization. More specifically, increased social disorder contributes to increased odds of adolescents being victimized at urban schools. Research evidence suggests a symbiotic relationship between school disorder, violence and victimization, and racial and ethnic segregation $[13,14,25,31]$. To that end, little is known about the distinct association between school contexts and school disorder.

6.1. Implications. These findings have important implications for school practice and policy. The significance of race and ethnicity, as well as school context, does matter in adolescents' experiences with violence and victimization at school. In recent years, school violence has been recognized as a national concern and has received considerable amount of media coverage. School districts nationwide have been mandated to develop or implement violence prevention programs and policies. Despite these efforts, research indicates that many of the antischool violence policies do not consider the unique vulnerabilities that affect the marginalized populations, such as racial and ethnic minorities $[5,25]$. There is no doubt that school administrators need to implement policies and practices that protect all adolescents from violence and victimization. It is imperative that school practitioners and administrators pay particular attention to factors that may affect marginalized students. To illustrate, an evaluation of the widely used Olweus Bullying Prevention Program found that the program was effective only for white students and not for racial and ethnic minority students [45, 46]. Violence prevention and intervention programs are only effective when they adequately address issues that are relevant to certain vulnerable and marginalized youth populations, such as less likelihood of racial and ethnic minority youth in seeking help and report their victimization [25, 47]. It is also evident that urban schools have increased levels of poverty as well as limited resources to ameliorate the violence that occurs within these schools [21-23, 25, 31]. Thus, continuing to provide educational opportunities that equivocate into educational progress and success, such as academic and sports activities, needs to remain a priority. School administrators need to continue their efforts in providing a safe and healthy school environment that fosters success and prosocial behavior.

This research has important implications for research on adolescent violence. According to the Centers for Disease Control and Prevention, adolescent violence occurring in schools is a top public health concern because students who are victimized in school are at a significant risk of experiencing physical health problems, emotional problems, and lower academic achievement. As previously noted, within thirty years, white Americans will represent less than half of the total adolescent youth population in the USA [10]. Hawkins ([35], page six) calls for additional research identifying the causes and extent of disparities in violence across multiple racial and ethnic groups. Thus, criminological research should place more emphasis on the significance of race and ethnicity in the occurrence of victimization as well as theories that can explicate adolescent violence, such as routine and activities theory.

6.2. Limitations and Future Directions. This study is not without any limitations. First, although the growing rate of racial and ethnic minority youth is attributed to immigration, this study did not consider immigration factors. 
Future research should consider whether factors associated with immigration influence the relationship between routine activities and adolescent violence across various school contexts. There is a growing body of criminological research that has established the association between assimilation and increased adolescent violence, which is often referred to as the "immigrant paradox." Researchers reveal counterintuitive findings that immigrant adolescents adapting to USA cultural and social norms may result in detrimental outcomes, such as increased engagement in crime, disorder, violence, and victimization within communities and schools (Desmond \& Kubrin, 2009 [50]) [48, 49]. Additionally, recent research found that the relationships between routine activities and adolescent school-based victimization are indeed moderated by immigrant generation status [48]. Future studies should consider if and how immigration mediates or moderates the link between routine activities and adolescent violence in school.

Second, qualitative research could better illuminate our understanding of the contextual factors that influence this study's quantitative examination of routine activities and adolescent violence across various school contexts. There are complexities and nuances with interracial friendships, tensions, and conflict across various school contexts. Brunson and Miller [25] also made it clear that, because conflict between adolescents can shape conflict in the schools, understanding how the community perpetuates inequality is a key towards understanding and addressing violence that occurs within school. Despite the limitations associated with this analysis, this study's findings provide avenues for future research on routine activities and adolescent violence across various school contexts.

\section{References}

[1] L. E. Cohen and M. Felson, "Social change and crime rate trends," American Sociological Review, vol. 52, pp. 170-183, 1979.

[2] L. E. Cohen, J. R. Kluegel, and K. C. Land, "Social inequality and predatory criminal victimization: an exposition and test of a formal theory," American Sociological Review, vol. 46, no. 5, pp. 505-524, 1981.

[3] M. Felson, Crime and Everyday Life, Pine Forge, Thousand Oaks, Calif, USA, 1998.

[4] D. C. Gottfredson, School and Delinquency, Cambridge University Press, Cambridge, UK, 2001.

[5] G. W. Muschert and A. A. Peguero, "The columbine effect and school antiviolence policy," Research in Social Problems and Public Policy, vol. 17, pp. 117-148, 2010.

[6] S. Nofziger, "Deviant lifestyles and violent victimization at school," Journal of Interpersonal Violence, vol. 24, no. 9, pp. 1494-1517, 2009.

[7] P. Wilcox, M. S. Tillyer, and B. S. Fisher, "Gendered opportunity? School-based adolescent victimization," Journal of Research in Crime and Delinquency, vol. 46, no. 2, pp. 245-269, 2009.

[8] A. A. Peguero, A. M. Popp, and D. J. Koo, "Race, ethnicity, and school-based adolescent victimization," Crime and Delinquency, 2011.
[9] P. Wilcox, K. C. Land, and S. A. Hunt, Criminal Circumstance: A Dynamic, Multicontextual Criminal Opportunity Theory, Aldine de Gruyter, Hawthorne, NY, USA, 2003.

[10] United States Census Bureau, Current Population Survey, U.S. Census Bureau, Population Division, Washington, DC, USA, 2010.

[11] R. Peterson, L. Krivo, and J. Hagan, The Many Colors of Crime: Inequalities of Race, Ethnicity, and Crime in America, New York University Press, New York, NY, USA, 2006.

[12] R. Benbenishty and R. A. Astor, School Violence in Context: Culture, Neighborhood, Family, School and Gender, Oxford University Press, New York, NY, USA, 2005.

[13] W. N. Welsh, "Effects of student and school factors on five measures of school disorder," Justice Quarterly, vol. 18, no. 4, pp. 911-947, 2001.

[14] W. N. Welsh, J. R. Greene, and P. H. Jenkins, "School disorder: the influence of individual, institutional, and community factors," Criminology, vol. 37, no. 1, pp. 73-114, 1999.

[15] A. A. Payne, "A multilevel analysis of the relationships among communal school organization, student bonding, and delinquency," Journal of Research in Crime and Delinquency, vol. 45, no. 4, pp. 429-455, 2008.

[16] A. A. Payne, D. C. Gottfredson, and G. D. Gottfredson, "Schools as communities: the relationships among communal school organization, student bonding, and school disorder," Criminology, vol. 41, no. 3, pp. 749-777, 2003.

[17] A. A. Peguero, "Opportunity, involvement, and student exposure to school violence," Youth Violence and Juvenile Justice, vol. 7, no. 4, pp. 299-312, 2009.

[18] A. A. Peguero and L. M. Williams, "Racial and ethnic stereotypes and bullying victimization," Youth \& Society, 2012.

[19] A. M. Popp and A. A. Peguero, "Routine activities and victimization at school: the significance of gender," Journal of Interpersonal Violence, vol. 26, no. 12, pp. 2413-2436, 2011.

[20] R. A. Astor, H. A. Meyer, and W. J. Behre, "Unowned places and times: maps and interviews about violence in high schools," American Educational Research Journal, vol. 36, no. 1, pp. 3-42, 1999.

[21] J. Kozol, Savage Inequalities: Children in America's Schools, Crown, New York, NY, USA, 1991.

[22] J. Kozol, the Shame of the Nation: The Restoration of Apartheid Schooling in America, Three Rivers Press, New York, NY, USA, 2005.

[23] V. M. Rios, Punished: Policing the Lives of Black and Latino Boys, New York University Press, New York, NY, USA, 2011.

[24] R. J. Durán, Gang Life in Two Cities: An Insider's Journey, Columbia University Press, New York, NY, USA, 2013.

[25] R. K. Brunson and J. Miller, "Schools, neighborhoods, and adolescent conflicts: a situational examination of reciprocal dynamics," Justice Quarterly, vol. 26, no. 2, pp. 183-210, 2009.

[26] E. B. Stewart, "School structural characteristics, student effort, peer associations, and parental involvement: the influence of school- and individual-level factors on academic achievement," Education and Urban Society, vol. 40, no. 2, pp. 179-204, 2008.

[27] E. B. Reeves, "The effects of opportunity to learn, family socioeconomic status, and friends on the rural math achievement gap in high school," American Behavioral Scientist, vol. 56, no. 7, pp. 887-907, 2012.

[28] C. J. Schreck, J. M. Miller, and C. L. Gibson, "Trouble in the school yard: a study of the risk factors of victimization at 
school," Crime and Delinquency, vol. 49, no. 3, pp. 460-484, 2003.

[29] S. Graham, A. Bellmore, A. Nishina, and J. Juvonen, “"It must be me": ethnic diversity and attributions for peer victimization in middle school," Journal of Youth and Adolescence, vol. 38, no. 4, pp. 487-499, 2009.

[30] A. Kupchik, Homeroom Security: School Discipline in an Age of Fear, New York University Press, New York, NY, USA, 2010.

[31] E. L. Portillos, J. C. González, and A. A. Peguero, "Crime control strategies in school: chicanos/as perceptions and criminalization," Urban Review, vol. 44, no. 2, pp. 171-188, 2012.

[32] N. L. Bracy, "Student perceptions of high-security school environments," Youth and Society, vol. 43, no. 1, pp. 365-395, 2011.

[33] E. A. Stewart, "School social bonds, school climate, and school misbehavior: a multilevel analysis," Justice Quarterly, vol. 20, no. 3, pp. 575-604, 2003.

[34] J. D. Burrow and R. Apel, "Youth behavior, school structure, and student risk of victimization," Justice Quarterly, vol. 25, no. 2, pp. 349-380, 2008.

[35] D. F. Hawkins, Violent Crime: Assessing Race \& Ethnic Differences, Cambridge University Press, Cambridge, UK, 2003.

[36] S. J. Ingels, D. J. Pratt, D. Wilson et al., Education Longitudinal Study of 2002: Base-Year to Second Follow-Up Data File Documentation, U.S. Department of Education, National Center for Education Statistics, Washington, DC, USA, 2007.

[37] Educational Longitudinal Study: 2002 Base Year Data File User's Manual, National Center for Education Statistics, Washington, DC, USA, 2004.

[38] B. Moon, H. W. Hwang, and J. D. McCluskey, "Causes of school bullying: empirical test of a general theory of crime, differential association theory, and general strain theory," Crime and Delinquency, vol. 57, no. 6, pp. 849-877, 2011.

[39] A. M. Popp, "The effects of exposure, proximity, and capable guardians on the risk of bullying victimization," Youth Violence and Juvenile Justice, vol. 10, no. 4, pp. 315-332, 2012.

[40] C. J. Schreck, R. A. Wright, and J. M. Miller, "A study of individual and situational antecedents of violent victimization," Justice Quarterly, vol. 19, no. 1, pp. 159-180, 2002.

[41] S. W. Raudenbush, A. S. Bryk, and R. Congdon, Hierarchical Linear Models, Scientific Software International, Lincolnwood, Ill, USA, 2008.

[42] D. Finkelhor and N. L. Asdigian, "Risk factors for youth victimization: beyond a lifestyles/routine activities theory approach," Violence and Victims, vol. 11, no. 1, pp. 3-19, 1996.

[43] B. S. Faircloth and J. V. Hamm, "Sense of belonging among high school students representing 4 ethnic groups," Journal of Youth and Adolescence, vol. 34, no. 4, pp. 293-309, 2005.

[44] K. E. Miller, M. P. Farrell, G. M. Barnes, M. J. Melnick, and D. Sabo, "Gender/racial differences in jock identity, dating, and adolescent sexual risk," Journal of Youth and Adolescence, vol. 34, no. 2, pp. 123-136, 2005.

[45] N. S. Bauer, P. Lozano, and F. P. Rivara, "The effectiveness of the Olweus Bullying Prevention Program in public middle schools: a controlled trial," Journal of Adolescent Health, vol. 40, no. 3, pp. 266-274, 2007.

[46] J. S. Hong, "Feasibility of the Olweus bullying prevention program in low-income schools," Journal of School Violence, vol. 8, no. 1, pp. 81-97, 2009.

[47] C. M. Rennison, "An investigation of reporting violence to the police: a focus on Hispanic victims," Journal of Criminal Justice, vol. 38 , no. 4, pp. 390-399, 2010.
[48] A. A. Peguero, "An adolescent victimization immigrant paradox? School-based routines, lifestyles, and victimization across immigration generations," Journal of Youth and Adolescence, 2013.

[49] H. Miller and C. L. Gibson, "Neighborhoods, acculturation, crime, and victimization among hispanics: the cross-fertilization of the sociologies of immigration and crime," Journal of Contemporary Criminal Justice, vol. 27, no. 1, pp. 4-17, 2011.

[50] S. A. Desmond and C. E. Kubrin, "The power of place: immigrant communities and adolescent violence," Sociological Quarterly, vol. 50, no. 4, pp. 581-607, 2009. 

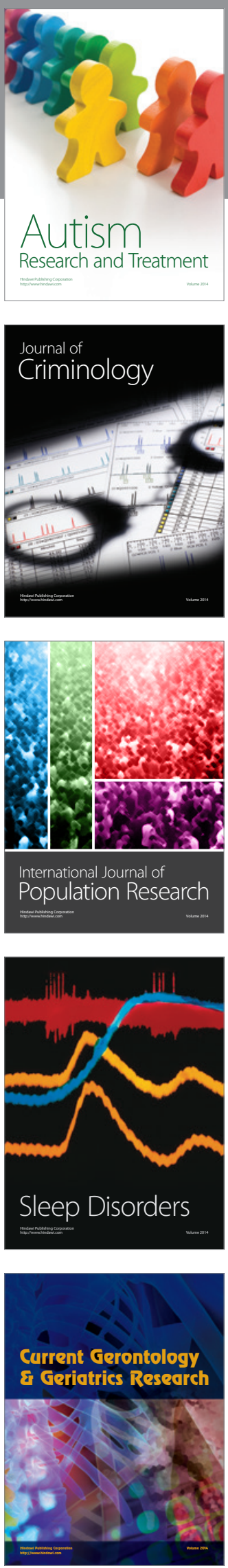
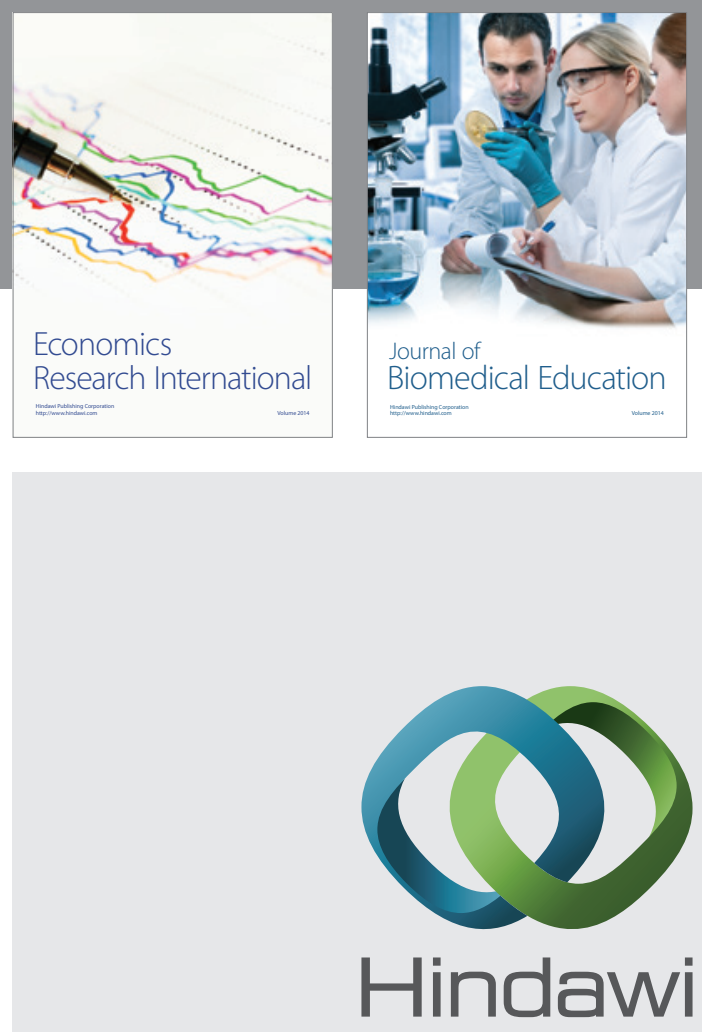

Submit your manuscripts at

http://www.hindawi.com
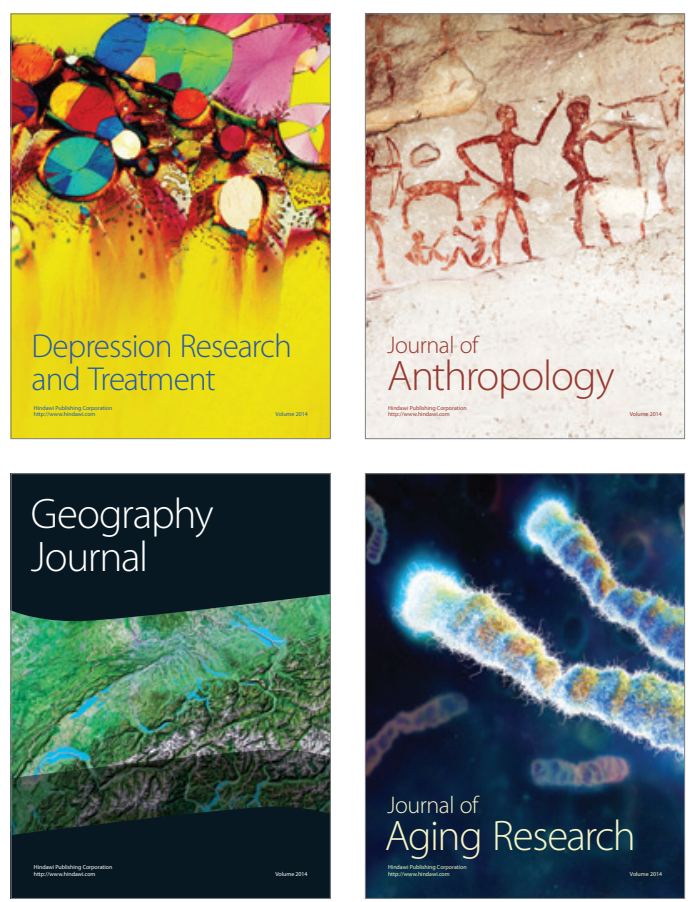
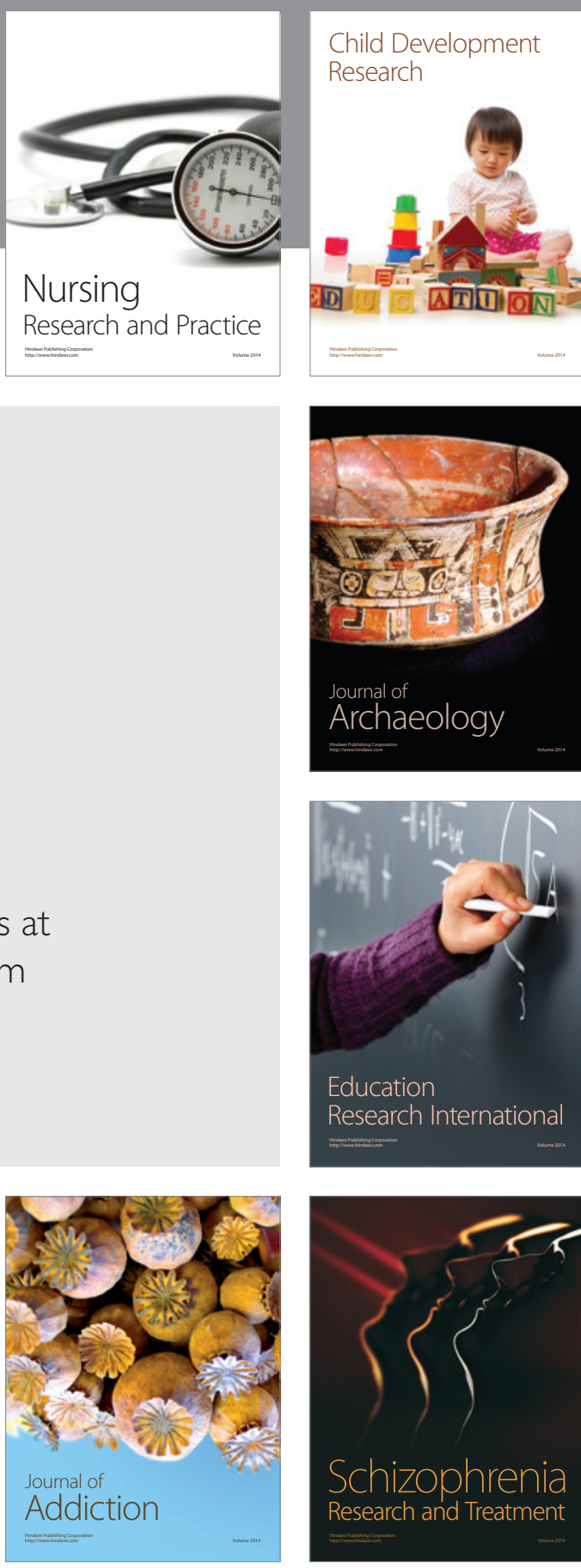

(D)
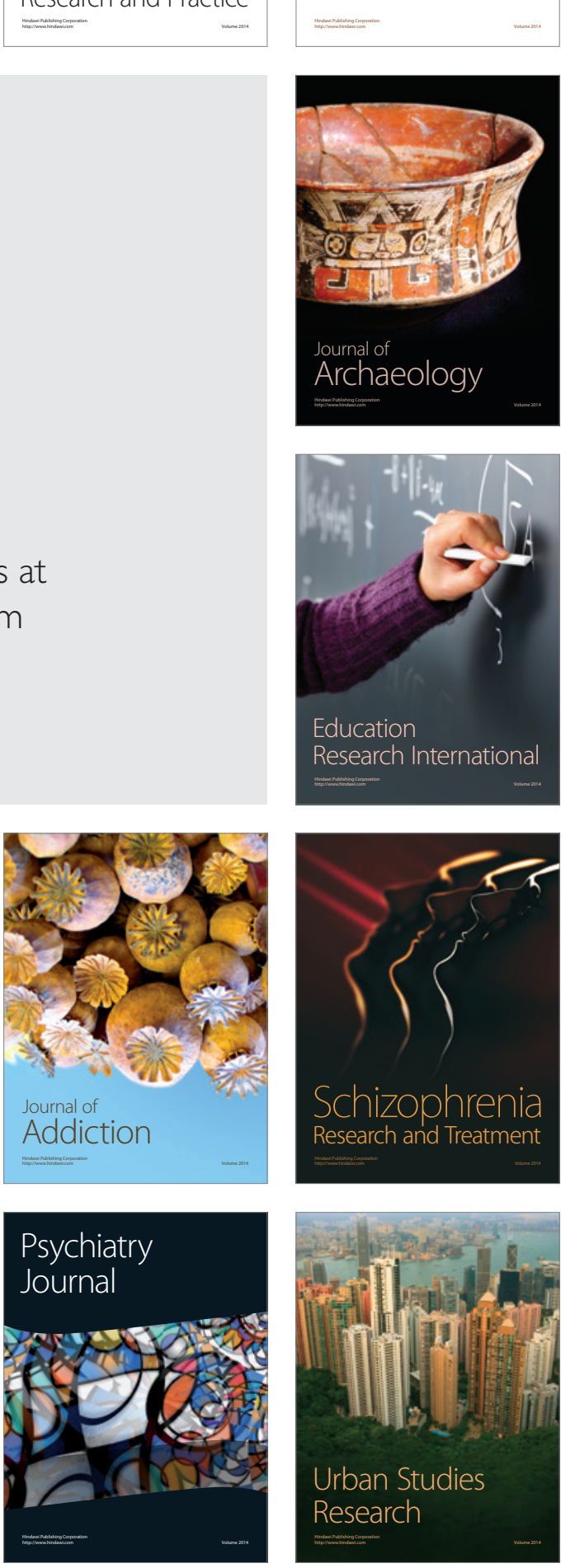